\title{
White Collar Punters: Stealing from the boss to gamble
}

\author{
Penny Crofts ${ }^{1}$
}

\begin{abstract}
Gambling provides a significant motivation for employee theft. Recent research suggests that problem gambling provides a motivation for at least $15 \%$ of employee thefts in New South Wales. Problem gamblers may steal from their places of employment either to finance their gambling or to repay gambling debts. The reasons why a person gambles excessively impact upon their offending patterns. Problem gamblers who believe that they will win, may initially 'borrow' money from work, in order to finance additional gambling to win back money they have lost. When they do not win, the continued irrational belief that they will win, provides the motivation to continue stealing in order to provide a big enough stake to win back the money they have lost and stolen. Additionally, if a person gambles to avoid stress or depression, and then steals from work to finance their gambling, this thieving can then become a major cause of stress in and of itself. This leads to sustained stealing from the workplace until the problem gambler is apprehended.
\end{abstract}

\section{Introduction}

Employee fraud is estimated to cost Australian businesses hundreds of millions of dollars a year (KPMG 2002; DCPC 2002:60). I have recently completed research that suggests that problem gambling provides a significant motivation for employee theft (Crofts 2002). This finding has since been supported by the Australian Institute of Criminology and Pricewaterhouse Coopers (2003) examination of serious fraud prosecutions heard in 1998 and 1999 in Australia and New Zealand. Both studies found that problem gamblers may steal either to finance their gambling or to repay gambling-related debts. This paper details the research positing a link between problem gambling and employee theft, and then analyses the relationship between the motivation to gamble excessively and criminal offending. I argue firstly, that the belief by gamblers that they will eventually win, provides a foundation for starting and then continuing to steal. Problem gamblers may steal from their employers in the belief that if they have money for a stake, they will be able to repay any prior thefts when they win. Secondly, many problem gamblers appear to rely on gambling to cope with negative affective states. For these gamblers, any thefts they have committed to finance their gambling exacerbates the need to gamble, as they become stressed, distressed and depressed about their thefts. From the present study, it appears that

* Financial assistance for this Project was provided by the New South Wales Govermment from the Casino Community Benefit Fund. The views expressed are the responsibility of the author and are not necessarily those of the casino.

1 Senior Lecturer, Faculty of Law, University of Technology, Sydney. Email: <penny@law.uts.edu.au>. 
people who gamble to avoid negative affective states will continue gambling until they are apprehended. As a consequence, situational safeguards against employee theft become an extremely important factor in terms of the amounts stolen by problem gamblers.

\section{Research regarding the relationship between gambling and crime}

Whilst there is a great deal of anecdotal information regarding the relationship between gambling and crime, research in this area is limited (Productivity Commission 1999a; 1999b; Sakurai \& Smith 2003). Available research focusing on persons receiving treatment for problem gambling has posited a link between problem gambling and crime (Blaszczynski \& McConaghy 1992). This study noted that employee theft was one of the major types of offences committed by problem gamblers to finance their gambling. One of the limitations of this research is that it cannot estimate the extent to which problem gambling impacts upon general crime statistics. This section briefly details the methodological approach to the present study and its weaknesses, to provide some guidance as to the reliability of the research results.

The study consisted of analysing case files between 1995 and 1999 at the Local and District Court levels at the Downing Centre, Sydney. The analysis of larceny by a servant/ clerk offences was part of a larger project (Crofts 2002). ${ }^{2}$ In total, 186 larceny by a servant/ clerk offence files were considered, 36 of which were characterised as gambling-related at the penultimate stage of research.

Case files of persons found guilty of specific property offences were scrutinised in order to determine whether or not the crime could be considered 'gambling-related'. To be classified as 'gambling-related' there had to be a causal relationship between gambling and crime. For example, if the defendant had a gambling problem but stole from his or her employer in order to buy alcohol, this file would be excluded as there was no apparent causal relationship between the offence and the defendant's gambling. Thus, the scope of the project specifically excluded offences committed by offenders who also gambled excessively. A broad definition of causation was adopted. Gambling did not have to be the sole cause of the crime. Rather, the classification scheme simply required a significant relationship. Thus, where it was unclear whether the defendant's crime was committed due to a drug or gambling problem, the file would be included.

If a case was classified as 'gambling-related', it was read more thoroughly in order to complete a questionnaire that sought to draw out salient details. Documents from the file were then photocopied and the originals were returned to the shelves. At best, this would involve making copies of the prosecution brief, pre-sentence reports, psychological reports, the person's criminal record and any other relevant information that could be used to establish an insight into the person's gambling, the commission of the offence and the court's response to it. At this stage, 36 of 182 larceny by a servant/clerk files were found to be 'gambling-related'.

2 Overall, 2776 case files were read to analyse the relationship between gambling and a variety of offences, including larceny, larceny of a motor vehicle, larceny by a servant, obtaining by false pretences, robbery offences and breaches of apprehended violence orders. Of these cases, 105 files exhibited a relationship between gambling and crime, with 63 case files containing sufficient information for the purposes of analysis. 
A questionnaire was then applied to the remaining 36 files. A further 9 files were then excluded due to insufficient information in the case file concerning the subject or the relationship between the subject's gambling and crime. Consequently, the 27 Local Court and/or District Court larceny by a servant/clerk case files recorded and analysed by this project involved matters:

- decided by Local or District Courts in NSW between 1995-1999;

- where the defendant was found guilty;

- where there was a larceny by a servant/clerk charge that was gambling-related; and

- with sufficient information in the files to provide information about the gambling problem and its relationship with the crime.

As this methodological approach was the first of its kind in gambling-related studies in the world, I will analyse the advantages and disadvantages of this approach briefly, to give some guidance as to the reliability of the findings. In methodological terms, the 'whole' that is represented by the sample is denoted by the sampling frame. The sampling frame is an objective list of the 'population' from which a researcher can make his or her selections (Denscombe 1998:17). The sampling frame in this research is the record at the Downing Centre of larceny by a servant/clerk case files where the offender is found guilty. The selection of the sampling frame has implications for the quality of the research.

This research examined 182 larceny by a clerk/servant files. Whilst this appears to be a small sample over the five years of cases examined, this sample is representative of the offence. Figures from the New South Wales Bureau of Crime Statistics highlight that the 182 larceny by a clerk case files considered covered almost all of the larceny by a clerk/ servant offences occurring between 1995-1999 (Fitzgerald 2002). The Bureau indicated that there were 3777 larceny by a clerk/servant guilty findings between 1995 to 1999 . These figures indicated the findings of guilt for individual charges, and it should be noted that in the present study, the subjects were found guilty of multiple charges of larceny by a clerk/ servant. In the 27 offence files considered 'gambling-related' there were at least 1616 charges for larceny by a servant/clerk. The number of charges were not indicated in the files of seven of the subjects, all of whom stole large amounts of money for long periods of time. Consequently, the sample of persons found guilty of larceny by a servant/clerk offences in NSW between 1995-1999 provides a representative cross-section of the whole (Denscombe 1998:12).

Although this research provides a representative cross-section of persons found guilty of larceny by a servant/clerk, this does not mean that the sampling frame exhaustively covers all employee theft. Firstly, research suggests that many employees stealing from their employers are not charged with criminal offences. In its most recent survey of business fraud, KPMG found that $62.6 \%$ of frauds reported in the survey were reported to the police. This leaves nearly $40 \%$ of known fraud matters handled without police involvement. A range of other responses were recorded, including internal and external investigations, or simply immediate dismissal of the employee in question (KPMG 2002). A 1993 survey by the Australian Institute of Criminology found that companies gave several reasons for not reporting fraud to the police, including 'lack of evidence', 'not serious enough', 'could do nothing' and 'inappropriate' (Walker 1994). Additionally, companies are also reluctant to report fraud due to a fear of 'sending good money after bad' or generating bad publicity. Companies may believe that it is impossible to recover losses through legal avenues and that the time and resources required to report an incident officially and to assist in its 
prosecution simply do not justify the likely return on investment (Drugs and Crime Prevention Committee 2002:38). Companies also usually have their own internal disciplinary procedures which deal with a wide range of rule violations, including dishonesty. Henry researched company responses to breaches of formal criminal law, and found that the bulk of violations were handled internally (Henry 1983).

Secondly, if offenders are charged with employee theft, they may not have been charged with the offence of larceny by a servant/clerk. Police have a great deal of discretion as to whether the offender is charged with larceny by a clerk/servant, larceny, obtaining by false pretences, embezzlement etc. The offence of embezzlement is closely related to the offence of larceny by a servant/clerk. In terms of covering the field, my project would have benefited greatly from considering embezzlement case files, particularly as there was such a high rate of gambling-related larceny by a servant offences. ${ }^{3}$ Although this project did not include embezzlement as one of the offences studied, figures from the New South Wales Bureau of Crime Statistics demonstrate that this exclusion does not dramatically affect the reliability of the figures. Between 1995 to 1999 , there were only 654 embezzlement as clerk or servant charges, in comparison with 3777 larceny by servant/clerk charges (Fitzgerald 2002).

Even if persons were charged and found guilty of a gambling-related larceny by a servant/clerk offence, this does not guarantee that they would be included in the present study. In the cases where a defendant has been charged and found guilty of a crime, even if a crime was gambling-related, this may not be disclosed to police (CCCJ 2000:90). The Productivity Commission noted that defendants are rarely probed for motive (1999a:H.17). Gambling is not automatically raised as an issue, in contrast with alcohol and drugs. Even if a crime has been identified by the offender or an agent of the criminal justice system as gambling-related, there is no guarantee that this will be recorded. Gambling problems tend not to be mentioned by defence or prosecution 'other than when they considered that to be in their best interests' (CCCJ 2000:89). The lack of automatic reference to gambling by police and in pre-sentence reports is understandable, particularly as judgments suggest that gambling is largely irrelevant to sentencing determinations.

The preceding analysis suggests that the present study underestimates the extent of employee theft in New South Wales. Employee theft may not be charged at all, or may be classified as an offence other than larceny by a servant/clerk. Furthermore, it can be asserted that the present study also underestimates the extent to which problem gambling provides a motivation for employee theft. Even if a person has been charged with larceny by a servant/clerk, the file may still not have been considered in this study, because there is no guarantee that any relationship between gambling and the commission of the crime would be disclosed and recorded. However, the Productivity Commission noted that defendants may claim the defence of gambling addiction as a mitigating factor in the hope of securing a more lenient sentence (1999a: H20). Additionally, another reason for claiming a nonexistent gambling addiction would be to keep any money stolen. Consequently, there may be subjects in this study pretending to be problem gamblers. From the information available in the files, it can be argued that the number of 'fake' problem gamblers is minimal for two major reasons. Firstly, at present, there is limited benefit to claiming to be a problem gambler in terms of sentencing. Secondly, many of the files contain information supporting subjects' claims of problem gambling. This may take the form of policing noting that the subject has not otherwise benefited from the stolen money, or psychological evaluations of

3 Future research should include both offences in order to consider adequately gambling-related crime. 
the subject as a problem gambler, evidence presented by family members, the subject being apprehended whilst gambling, or bank records revealing that the stolen monies were spent at clubs or casinos. Many of the files note that the subjects have large debts despite the money stolen and that they have benefited little as a consequence of gambling.

\section{The relationship between problem gambling and employee theft}

The present study points towards a causal link between problem gambling and the commission of criminal offences in accordance with the earlier Blaszczynski and McConaghy study on pathological gamblers (1992). Of the 182 larceny by a clerk/servant files examined, 36 were gambling-related. This means that almost 1 in $5(19.7 \%)$ of larceny by a clerk offences were gambling-related. At the final research stage, 27 out of the 182 larceny by a clerk/servant files examined were gambling-related and contained sufficient information for the purposes of research. Thus, even on the basis of including only these files, $14.8 \%$ of larceny by a clerk offences examined in New South Wales were arguably gambling-related. Given that the shortcomings in the methodological approach indicate an underestimation of employee theft and gambling as a motivation, my research highlights problem gambling as a significant motivator for employee theft.

Amounts stolen by persons charged with larceny by a servant/clerk are frequently large. Between them, the 27 subjects stole more than $\$ 2494309$. Amounts stolen ranged from $\$ 950$ to $\$ 425000$. The average amount stolen by each subject from their employer was $\$ 95935$. The median amount stolen was $\$ 44000$. The duration of the offences ranged from one-off thefts to stealing over a period of 10 years.

Lesieur (1984) has outlined the events that may lead some problem gamblers to commit criminal offences. Problem gamblers may initially draw on their savings and then make cash advances on their credit cards, borrow from friends and family, or take out loans from banks or other financial institutions to obtain money for gambling or to pay gambling debts. Problem gamblers may then borrow from loan sharks, or resort to selling personal or family property to obtain finances for gambling. Faced with mounting financial difficulties and gambling-related debts, when all these legal sources of gambling funds are exhausted, problem gamblers may resort to illegal activities to obtain money.

It appears that the majority of problem gamblers commit offences that are directly related to their gambling. Of the 27 subjects convicted of larceny by a servant/clerk offences in the study, 24 of them committed the offence(s) in order to gamble. A direct relationship between gambling and crime existed over protracted time periods. For example, a bank clerk stole $\$ 96000$ from customer bank accounts and credited his own accounts with the proceeds. He spent all the money from his thefts on poker machines at lunch time. Another clerk stole more than $\$ 425000$ over 10 years from her employers, spending all of the stolen money gambling on poker machines at the local clubs. Her defence lawyer noted that she had caused financial ruin for herself and her husband. One subject stole $\$ 218000$ from the company trust account over a 4 year period. The police fact sheet noted that none of the money could be located and there was evidence that the vast majority of the funds had been squandered by the subject through gambling.

A more indirect relationship between gambling and the commission of criminal offences was established in only 2 of the larceny by a servant/clerk offender files. These subjects stole in order to meet debts and financial shortfalls as a consequence of gambling. The case of one subject is a particularly good example of an indirect relationship between gambling 
and the commission of the crime. This subject had had a 'rampant gambling habit' five years prior to the current offences for which he was charged. At the time of his earlier gambling habit, the subject had committed fraud offences to pay for his gambling habit. Upon being charged for this first batch of offences, the subject had joined Gamblers Anonymous and also received treatment with Professor Blaszczynski and stopped gambling. He claimed he no longer felt the temptation to gamble and was quite sure he would not do so. The subject repaid his employers from the first group of fraud offences by mortgaging his home. However, he had not repaid the SP Bookie the $\$ 150000$ he had borrowed to gamble five years earlier. The subject therefore stole $\$ 115311$ to repay a gambling debt he had incurred from his earlier gambling habit.

There was one case included in this study where the link between gambling and the commission of the crime was less direct. This subject spent part of the money stolen on gambling, with the other half spent on massage parlours, restaurants and clothes. He stated that he had not needed the money, but committed the crime because of opportunism. Consequently, for this subject, gambling was $a$ motivation for the commission of crime, rather than the motivation.

\section{Motivation to gamble}

This section considers some of the pathways to problem gambling and how this may impact upon offending patterns. Firstly, I focus upon the development of irrational cognitive schemes, identified by Blaszczynski (2000) as common to all problem gamblers. Secondly, I consider a smaller subgroup of problem gamblers, those who could be classified as what Blaszczynski (2000) would term 'emotionally vulnerable' pathological gamblers. I extend Blaszcsynski's ideas to argue that both these characteristics contribute to offending patterns of problem gamblers.

\section{Development of Cognitive Schemes}

The development of cognitive schemes by problem gamblers contributes to sustained offending patterns. Theorists in this area have pointed to the development of cognitive schemes as common to problem gamblers (Blaszczynski 2000). Early and repeated wins result in irrational belief structures that promote gambling as an effective source of income:

The reinforcing properties of gambling and the irrational cognitive schemas combine to consolidate and strengthen habitual gambling practices ... When gamblers lose they attempt to recoup their losses through further chasing, which results in accumulated financial debts. Despite acknowledging the reality that gambling led them into financial problems, they irrationally believe that gambling will solve their problems (Blaszczynski 2000:4).

The belief structures shape illusions of control, superstitious thinking, incorrect understandings of probability and erroneous perceptions. This relates to concerns noted by the Productivity Commission (1999a:7.7) that promotional activities of the gambling industry may compound erroneous beliefs that gamblers have about winning.

The development of irrational cognitive schemes impacts upon offending patterns of problem gamblers, particularly if gamblers start chasing their losses. Lesieur provided a detailed account of chasing losses in The Chase (1984). As debts increase, the need for a 'big win' becomes paramount, and an escalation of illegally obtained moneys may occur to buy time by covering one's tracks or to have a stake to gamble to win to pay back debts. This can be seen to demonstrate not only a desire to continue gambling, but also the sustained belief in the face of all their experiences to the contrary that they can make money from gambling. Many of the subjects here exhibited a propensity to chase their losses. 
Subjects would 'borrow' money from their workplace to finance their gambling. Their intention was to repay the money taken from work with a win from gambling. Upon losing, the subject would then 'borrow' more money with the hope of a 'big win' to repay the increasing amounts of money taken.

Additionally, the sustained belief that they will back the money they have stolen, will also encourage problem gamblers to steal larger and larger amounts from their employers, to provide a sufficiently large stake for a big win. Subjects in the present study who stole for lengthy periods of time from their employers tended to escalate their thefts over time, both in terms of amounts stolen and the frequency of the thefts.

Consequently, if people believe, despite their experiences to the contrary, that they will win at gambling, this can provide a justification for sustained thieving from the workplace. The belief that they will eventually win, promoted by gambling outlets, reduces the likelihood they will turn themselves in. The irrational cognitive scheme suggests that if they are still gambling, there is the possibility they will be able to repay the money they have stolen. Clearly, continuing to steal from the workplace is also a gamble-turning oneself in precludes any chance of 'winning', whereas stealing from work at least allows a chance, albeit a small one, of winning back the money.

\section{Emotionally vulnerable gamblers}

The reasons why a person gambles also contribute to offending patterns. Blaszczynski (2000:4) cites studies demonstrating that gambling produces a state of subjective excitement, increased heart rate and dissociation. Wins produce states of excitement that are described as equivalent to a 'drug induced high'. Excitement can be experienced in anticipation, during or in response to exposure to gambling situations or cues. Accordingly, Blaszczynski asserts that this process of conditioning can be used to explain gambling as an addiction produced by the effects of positive and negative conditioning, tolerance and withdrawal. Gamblers commonly describe feeling that they were in a 'zone' when gambling, where outside influences are less apparent and less affective. Gambling is seen as an 'escape' or a 'zone', and is seen as a 'way out'.

For some gamblers, this 'escape' or 'zone' provides the major motivation for their gambling. Blaszczynski (2000:5-6) labels these people as 'emotionally vulnerable gamblers'. This subgroup of problem gamblers is characterised by the presence of predisposing psychological vulnerability factors where participation in gambling is motivated by a desire to meet specific psychological needs and/or modulate affective states. This subgroup manifests a history of problem gambling in the family, neurotic personality traits, negative developmental experiences and adverse life events. These problems may accumulate to produce an emotionally vulnerable gambler.

According to Blaszczynski, this subgroup displays higher levels of premorbid psychology, particularly depression, anxiety, substance dependence and deficits in their ability to cope with and manage stress. Gamblers within this group cannot express their emotions directly, and they show a tendency to engage in passive aggressive or avoidance behaviours. These gamblers see gambling as a means of achieving a state of emotional escape through the effect of dissociation on mood alteration. Blaszczynski (2000:6) notes that because of their negative developmental history and poor coping skills, these gamblers are too fragile to maintain sufficient control over behaviour to permit controlled gambling. 
Blaszczynski suggests that there are two other subgroups of problem gamblers: the 'normal' problem gambler and the 'impulsive gambler'. According to Blaszczynski, 'normal' problem gamblers may meet formal criteria for pathological gambling at the height of their gambling disorder, but there is an absence of any specific premorbid psychopathology. These gamblers can therefore be seen as occupying the diffuse domain between regular-heavy and excessive gambling. Excessive gambling occurs because of bad judgments and/or poor decision-making structures, which are independent of any 'intrapsychic' disturbance. A preoccupation with gambling, chasing losses, substance dependence and anxiety and depression are all an end response to the financial pressures caused by continual losses. 'Normal' problem gamblers are more motivated to seek treatment, comply with instructions and, after treatment, are able to achieve controlled levels of gambling. Consequently, counselling and minimal intervention programs are of benefit.

In contrast, Blaszczynski defines impulsive problem gamblers as having neurological or neurochemical dysfunction reflecting impulsivity and attention-deficit disorders (2000:67). Blaszczynski details research suggesting that impulsivity precedes gambling, and is a good predictive factor for severity of involvement in at least a subgroup of gamblers. He argues that gamblers manifest differential responses to reward and punishment because of their biologically-based impulsivity. These gamblers demonstrate a marked propensity for seeking out rewarding activities, they are unable to delay gratification and have a diminished response to punishment. When the consequences of their actions are painful, they fail to modify their behaviour. Blaszczynski (2000:7) states that impulsive gamblers display a broad spectrum of behavioural problems which are independent of gambling, including substance abuse, suicidality, irritability, low tolerance for boredom and criminal behaviours. Characteristics of this group are poor interpersonal relations, excessive alcohol and poly-drug experimentation, non-gambling-related criminality and a family history of anti-social behaviour and alcoholism. For this group, gambling commences at an early age and rapidly escalates in intensity and severity, occurs in binge episodes and is associated with early gambling-related criminality. These gamblers are less motivated to seek treatment in the first instance, have poor compliance rates and respond poorly to any form of intervention.

The majority of subjects in the present study can be categorised as emotionally vulnerable gamblers, as they gambled to deal with and/or avoid stress or depression. For example, one subject stated that she had had a fascination with gambling for as long as she could remember. She placed bets on the trots at six years of age with her father. The subject's parents divorced when she was nine years of age. She then lived with her de facto father who had problems with alcohol, gambling and violence, at times stalking the family with a gun. At the time of the offences, he was still threatening her and her family. After the birth of her son, the subject maintained that she became bored with the isolation of being house bound and so became increasingly attracted to poker machines for an escape mechanism rather than a means to make money. The subject was also depressed trying to cope with her son's poor health. Her bets increased upon the breakup of her relationship with her de facto. She also found a correlation between depression and the size of her bets. The proceeds of her thefts typically went to her betting at the local RSL club. The subject stated that she did not care if she won, but she was obsessed with the escape and preoccupation of playing the poker machines. 
There are two ways in which the reliance upon gambling to deal with negative affective states can impact upon offending patterns. Firstly, the thefts from work may exacerbate the desire to gamble. These people may start gambling in order to deal with a negative emotional state. Unfortunately, gambling tends to overwhelm whatever original problem the subjects were seeking to cope with, as it is usually more expensive than any other problem they may have. Whilst it may appear self-evident that people who are getting away with crime will continue until they are apprehended, it is arguable that the need to gamble to deal with negative affective states impacts directly on the sustained offending patterns of problem gamblers stealing from their employers. The majority of the subjects charged with larceny by a servant in the present study were otherwise law-abiding, with no prior criminal records. Many stole from their employers for years, and expressed awareness that what they were doing was wrong and caused them great distress and stress. Some left clues about their thefts for their employers, some expressed relief when they were apprehended, confessing fully to police. These subjects were willing to continue stealing from their employers for such long periods of time because of the overwhelming need to gamble overcoming any concerns regarding apprehension or immorality. Their need to gamble was in fact fuelled by awareness and concerns about the wrongfulness and riskiness of their thefts.

Consequently, it is arguable that problem gamblers who are motivated to gamble to avoid negative emotional states are likely to continue stealing from work until apprehended. These problem gamblers originally start gambling to avoid negative emotional states as a consequence of disparate stressors and/or trauma, and are then caught in a vicious circle, where they need to steal more in order to finance their gambling, but these thefts fuel their desire to gamble.

Additionally, the motivation to gamble may contribute to offence patterns by providing a justification for the offence. Many of the subjects charged with larceny by a servant stated that they gambled in part because they were stressed as a consequence of their employment. For example, one subject started gambling to avoid reality and worries including raising three children whilst doing shift work. She had initially hoped for a 'big win' but gradually gave up on that possibility and just gambled to avoid reality. The psychologist stated that the subject relied on gambling to handle unhappy feelings, but once this habit had been established, she needed money to finance the gambling.

Promotion to a demanding position was cited by some subjects as the trigger for their gambling. For example, one subject claimed that his gambling increased as a result of his father dying and the stress due to his promotion to the position of manager. The subject stated that he worked 60 hours a week and had 42 staff. Another subject stated that she started gambling to escape the stress of her job after promotion, as she was frequently on call and required to respond to workplace demands out of hours. She then became addicted to poker machines and took money from work to recoup her losses. In addition, she also considered that she was making up for being underpaid. Similarly, one woman cited work stress as a major contributor to her gambling addiction. She said that when she was promoted to a management position she was required to reach daily and weekly targets and she found this highly stressful.

Another subject identified two incidents that he considered critical to increasing his bets and consequently stealing. Both incidents occurred when his employer demanded that the subject and his staff were responsible for losses that the business had suffered. The first event involved some misplaced goods, whilst the second related to money being lost in the office. In order to pay back the money, the subject started gambling with his own savings, 
and after he lost, he took money from the till with a view to recoup his losses and to pay back his employer. Consequently, problem gamblers may perceive their employment as the cause of their stress, and thefts from work to finance stress relieving gambling could be seen as justified.

\section{The absence of a capable guardian}

The absence of a capable guardian is always an important factor in the commission of crime (Cohen \& Felson 1979). Given that emotional problem gamblers will, in the main, continue to steal until apprehended, the absence of a capable guardian is particularly important. In many of the larceny by a servant cases, the subjects committed offences over long periods of time, in the absence of effective auditing procedures. It should also be noted that many of these subjects were not in the upper echelons of their companies, but took advantage of the trust that was invested in them in various clerical, administrative or low management positions. The most extreme example was the theft by a clerk of more than $\$ 425000$ over ten years from her employers. This was possible because her employers did not use proper auditing methods and there was some confusion when electronic records replaced a manual financial recording system. In the three years prior to being charged the subject had left clues so that she would be caught.

In another case, it was noted in the file that the auditor was facing civil action for recovery of the money stolen. This subject stole $\$ 246000$ from her employers over a period of five years. She was permitted to become a signatory to the business cheque account, and then wrote cheques to fictitious businesses which she deposited in her own account. The auditing procedures used by the business were primitive and, as a consequence, the auditor was facing civil action. Over the five years, the accountants did not ever compare the bank statements with the financial ledgers. Another subject stole $\$ 80000$ over a period of three years. He worked for the State Rail Authority and was discovered after an audit of his station's books. Another subject was able to steal $\$ 220000$ over a 7 year period by paying himself overtime and overpaying other employers and then intercepting the money. A significant factor that facilitated the process was that he was able to pay himself his own salary. The subject had minimal supervision. Internal and external audits were completed regularly, but they failed to pick up the discrepancies in payments.

The methods used by subjects to steal from their employers were simple but effective, due to the absence of internal security. Several subjects generated false refunds for products and kept the money. A cashier stole $\$ 145000$ by pocketing the proceeds of commercial sales and paper work that could be linked to the transactions. A teller for a security transport company stole $\$ 18350$ by removing sums of $\$ 2$ coins in multiples of $\$ 50$ from pre-counted bags that contained $\$ 2000$.

Several of the subjects illegally sold company goods to obtain money for gambling. For example, one subject sold more than 11000 bags of concrete to third parties over three years and kept the money from the sales. The company estimated the loss to be $\$ 70000$. The thefts were revealed in a stock take, whereupon the subject confessed. A manager at a supermarket arranged for goods to be picked up from the supermarket loading dock and sold to unknown parties. He sold $\$ 26000$ worth of perishable goods this way over one year. He would also pocket cheques paid by companies for goods delivered and then ring up sales of minimal amounts on the till. 
Another subject had previously been convicted of larceny by a servant offences for taking $\$ 42000$ from the club at which he had worked as a manager. He was on a good behaviour bond at the time of the second offences. With the permission of the court, the subject was allowed to work in the club industry provided the board of directors did not allow the subject to have independent access to the club's financial affairs. The club was aware of his prior offences. Over time, the subject was able to gain the trust of the board and became responsible for the banking and preparation of banking records. In part, the subject was able to convince the board of his trustworthiness because of his commitment to Gamblers Anonymous and his continued therapy. The subject then stole $\$ 115000$ by falsifying the entries in different accounts and purchasing rubber stamps that looked like bank stamps. These stamps were then used to create the impression that deposits had been made in the accounts in question. The subject also created false bank and government duty charges in the account in order to further the appearance of normality. The fraud was only discovered when the annual auditor telephoned the bank and asked for the balance, and was advised that it was nearly empty.

\section{Conclusion}

Problem gambling provides a significant motivation for employee theft. The present study suggests that at least $15 \%$ of employee theft is motivated by the need to finance gambling or to pay off gambling-related debts. The reasons why a person gambles also impacts upon their offending patterns. The irrational belief that they will win from gambling provides a motivation to 'borrow' from work initially in order to win back any losses. Additionally, if a person gambles to avoid negative affective states, then this will contribute to sustained thieving from the workplace as thefts become a stressor in and of themselves. Problem gamblers are caught in a vicious circle. They may originally start gambling to avoid disparate stresses or trauma, and then 'borrow' from the workplace to finance further gambling. These thefts from the workplace then cause further stress, exacerbating the need to gamble, and hence, the need to continue stealing from work to escape that stress. Thus emotionally vulnerable problem gamblers once they commence stealing from the workplace, are likely to continue stealing, until they are apprehended. Accordingly, employers need to utilise good auditing practices to protect against internal thefts that are motivated by gambling.

Until recently, it was impossible to quantify the relationship between problem gambling and crime. This study highlights that gambling provides a significant motivation for employee theft. Case files demonstrated the high price of problem gambling, with subjects losing their homes, families, employment and their liberty. Studies such as this raise serious questions about governmental financial dependence upon and active promotion of gambling.

\section{References}

Australian Institute of Criminology \& Pricewaterhouse Coopers (2003) Serious Fraud in Australia and New Zealand, Research and Public Policy Series, no 48, Australian Institute of Criminology, Canberra.

Blaszczynski, A (2000) 'Pathways to Pathological Gambling: Identifying Typologies', eGambling, vol 1, pp 1-13. 
Blaszczynski, A \& McConaghy, N (1992) Pathological Gambling and Criminal Behaviour, Report to the Criminology Research Council. Australian Institute of Criminology, Canberra.

Blaszczynski, A \& McConaghy, N (1994) 'Criminal Offences in Gamblers Anonymous and Hospital Treated Pathological Gamblers', Journal Of Gambling Studies, vol 10, no 2, pp 99-127.

Centre for Criminology and Criminal Justice, Monash University (2000) The Impact of Gaming Statistics: Project Report, prepared for the Victorian Casino and Gaming Authority, Melbourne, Victoria.

Cohen, L \& Felson, M (1979) 'Social Change and Crime Rate Trends: A routine activity approach', American Sociological Review, vol 44, pp 588-608.

Crofts, P (2002) Gambling and Criminal Behaviour: An Analysis of Local and District Court Cases, report submitted to the New South Wales Racing and Gaming Authority. Financed by the NSW Casino Community Benefit Fund, NSW, Australia. Available at $<$ www.law.usyd.edu.au/ criminology/>.

Denscombe, M (1998) The Good Research Guide: for small scale social research projects, Open University Press, Buckingham, Philadelphia.

Drugs and Crime Prevention Committee, Parliament of Victoria (DCPC) (2002) Inquiry into Fraud and Electronic Commerce: Emerging Trends and Best Practice Responses, Discussion Paper, October, Government Printer for the State of Victoria, Victoria.

Fitzgerald, J (2002) Larceny as a servant and related property offences; 1995-1999, email sent by Fitzgerald as Information Officer of the New South Wales Bureau of Crime Statistics upon request.

Graycar, A \& Smith, R (2002) Identifying and Responding to Corporate Fraud in the 21st Century, paper presented to the Australian Institute of Management, Australian Institute of Criminology, Sydney.

Hagan, F (1993) Research Methods in Criminal Justice and Criminology, MacMillan Publishing, New York.

Henry, S (1983) Private Justice: Towards Integrated Theorising in the Sociology of Law, Routledge Kegan Paul, London.

KPMG (2002) Fraud Survey 2002, KPMG Australia, Sydney, <http://www.kpmg.com.au/ content/Services/Services/Financial_Advisory_Services/Forensic_Overview/docs/ $6208 \% 20$ Fraud\%20Survey\%202002.pdf>.

Lesieur, H (1984) The Chase: Career of the Compulsive Gambler, Schenkman, Cambridge.

Lesieur, H \& Klein, R (1985) Prisoners, Gambling and Crime, paper presented at the Annual Meeting of the Academy of Criminal Justice Sciences, Las Vegas.

Productivity Commission (1999a) Australia's Gambling Industries: Draft Report, July, AusInfo, Canberra, Australia. 
Productivity Commission (1999b) Australia's Gambling Industries: Report No. 10, AusInfo, Canberra, Australia.

Sakurai, Y \& Smith, R (2003) 'Gambling as a Motivation for the Commission of Financial Crime', Trends and Issues in Crime and Criminal Justice, Australian Institute of Criminology, Canberra.

Walker, J (1994) The First Australian National Survey of Crimes Against Businesses, Australian Institute of Criminology, Australia. 